\title{
Streptococcal M1 Protein-Provoked CXC Chemokine Formation, Neutrophil Recruitment and Lung Damage Are Regulated by Rho-Kinase Signaling
}

\author{
Songen Zhang ${ }^{\text {a }}$ Milladur Rahman $^{\text {a }}$ Su Zhang $^{\text {a Heiko Herwald }}{ }^{b}$ \\ ${\text { Zhongquan } \mathrm{Q}^{\mathrm{a}}{ }^{\text {Bengt Jeppsson }}{ }^{\mathrm{a}} \text { Henrik Thorlacius }}^{\mathrm{a}}$ \\ ${ }^{a}$ Department of Clinical Sciences, Section for Surgery, Malmö University Hospital, Lund University, Malmö, and \\ ${ }^{b}$ Section for Clinical and Experimental Infection Medicine, Lund University, Lund, Sweden
}

\section{Key Words}

Chemokines $\cdot$ Kinases $\cdot$ Leukocytes $\cdot$ Lung $\cdot$ Sepsis

\begin{abstract}
Streptococcal toxic shock syndrome is frequently caused by Streptococcus pyogenes of the M1 serotype. The aim of this study was to determine the role of Ras-homologous (Rho)kinase signaling in $\mathrm{M} 1$ protein-provoked lung damage. Male C57BL/6 mice received the Rho-kinase-specific inhibitor $\mathrm{Y}-27632$ before administration of M1 protein. Edema, neutrophil accumulation and CXC chemokines were quantified in the lung $4 \mathrm{~h}$ after $\mathrm{M} 1$ protein challenge. Flow cytometry was used to determine Mac- 1 expression. Quantitative RT-PCR was used to determine gene expression of CXC chemokine mRNA in alveolar macrophages. M1 protein increased neutrophil accumulation, edema and CXC chemokine formation in the lung as well as enhanced Mac- 1 expression on neutrophils. Inhibition of Rho-kinase signaling significantly reduced M1 protein-provoked neutrophil accumulation and edema formation in the lung. M1 protein-triggered pulmonary production of CXC chemokine and gene expression of CXC chemokines in alveolar macrophages was decreased by Y-27632. Moreover, Rho-kinase inhibition attenuated M1 protein-induced Mac-1 expression on neutrophils. We con-
\end{abstract}

clude that Rho-kinase-dependent neutrophil infiltration controls pulmonary tissue damage in response to streptococcal M1 protein and that Rho-kinase signaling regulates M1 protein-induced lung recruitment of neutrophils via the formation of CXC chemokines and Mac-1 expression.

Copyright $\odot 2012$ S. Karger AG, Basel

\section{Introduction}

The microbial etiology of septic shock has traditionally been dominated by Gram-negative bacteria. However, a recent resurgence of Gram-positive bacterial infections has markedly changed the microbial etiology in septic patients [1-3]. Streptococcus pyogenes is a common cause of Gram-positive infections presenting as uncomplicated cases of pharyngitis to severe and fatal conditions, such as streptococcal toxic shock syndrome (STSS). STSS is an insidious condition associated with a mortality rate surpassing 50\% [4-6]. S. pyogenes expresses a versatile spectrum of virulence factors, such as M proteins; up to now, more than 80 different $M$ serotypes have been described. Importantly, convincing data have shown that the M1 serotype is most commonly associated with STSS [4]. M1 protein is a potent stimulator of the innate immunity trigger-

\section{KARGER}

Fax +4161306 1234

E-Mail karger@karger.ch

www.karger.com
(C) 2012 S. Karger AG, Basel

$1662-811 X / 12 / 0044-0399 \$ 38.00 / 0$

Accessible online at:

www.karger.com/jin
Dr. Henrik Thorlacius

Department of Clinical Sciences, Section for Surgery

Malmö University Hospital, Lund University

SE-205 02 Malmö (Sweden)

Tel. +46 40331 000, E-Mail henrik.thorlacius@med.lu.se 
ing neutrophil [5] and monocyte activation [7]. It forms complexes with fibrinogen, which activate neutrophils by binding to beta 2 integrins [5]. Neutrophils constitute the first line of defense against invading microorganisms but excessive activation and infiltration of neutrophils is also known to be a rate-limiting step in acute lung injury $[7,8]$. It is widely considered that the lung is the most critical organ involved in STSS patients $[9,10]$. Extravascular accumulation of neutrophils at sites of inflammation is regulated by adhesion molecules, including P-selectin and Mac-1 as well as CXC chemokines, such as macrophage inflammatory protein-2 (MIP-2) and cytokine-induced neutrophil chemoattractant (KC) [11-13]. A recent study demonstrated that M1 protein-induced pulmonary infiltration of neutrophils is critically dependent on the formation and action of CXC chemokines [14]. Thus, the chemokine-mediated mechanisms behind the accumulation of neutrophils in the lung are relatively well known, but the signaling pathways controlling M1 protein-provoked accumulation of neutrophils and lung injury remain elusive.

Extracellular stress situations, such as ischemia and infection, trigger intracellular signaling cascades converging on specific transcription factors regulating the gene expression of inflammatory mediators $[15,16]$. This signal transmission is largely regulated by intracellular kinases phosphorylating downstream targets [17]. For example, small (approx. $21 \mathrm{kDa}$ ) guanosine triphosphatases of the Ras-homologous (Rho) family and one of their effectors, Rho-kinase, are known to act as molecular switches regulating numerous important cellular functions, such as cytoskeleton organization, cell adhesion, reactive oxygen species formation and oncogenic transformation $[17,18]$. Moreover, a previous study demonstrated that Rho-kinase is an important regulator of chemoattractant-induced neutrophil migration in vitro [19]. Notably, Rho-kinase inhibitors have been demonstrated to ameliorate reperfusion and endotoxemic injury in the liver [20] as well as protecting against tissue fibrosis [21], obstructive cholestasis [22], intestinal ischemia [23] and pulmonary hypertension [24]. Previous studies have shown that CXC chemokine formation in acute pancreatitis [25], colonic ischemia-reperfusion [23] as well as cholestatic [22] and endotoxemic [20] liver injury is regulated by Rho-kinase. However, the role of Rho-kinase signaling in regulating CXC chemokine formation, neutrophil recruitment and tissue edema in M1 protein-induced acute lung injury is not known. Another group of significant kinases are mitogen-activated protein kinases (MAPKs), including p38 MAPK, extracellular signal-regulated protein kinases (ERK1/2) and c-Jun $\mathrm{NH}_{2}$-terminal protein kinases (JNKs) [26]. Signal transduction through MAPKs has been shown to control the production of inflammatory cytokines and chemokines [27, 28]. Notably, we recently observed that $\mathrm{p} 38 \mathrm{MAPK}$ is a key molecule in regulating M1 protein-induced neutrophil infiltration and lung damage [29].

Based on these considerations, the aim of this study was to define the functional significance of Rho-kinase signaling in regulating CXC chemokine production, neutrophil activation and recruitment as well as edema formation and p38 MAPK activity in acute lung injury provoked by streptococcal M1 protein.

\section{Materials and Methods}

\section{Animals}

All experimental procedures were performed in accordance with the legislation on the protection of animals and were approved by the Regional Ethical Committee for Animal Experimentation at Lund University, Sweden. Male C57BL/6 mice weighing 23-25 g were used for experiments and kept under standard laboratory conditions, maintained on a 12-12 h light-dark cycle and fed a laboratory diet and water ad libitum. Animals were anesthetized with $7.5 \mathrm{mg}$ of ketamine hydrochloride (HoffmanLa Roche, Basel, Switzerland) and $2.5 \mathrm{mg}$ of xylazine (Janssen Pharmaceutica, Beerse, Belgium) per 100-g body weight.

\section{Experimental Model}

M1 protein was purified from the isogenic mutant MC25 strain (derived from the AP1 S. pyogenes strain 40/58 from the WHO Collaborating Centre for References and Research on Streptococci, Institute of Hygiene and Epidemiology, Prague, Czech Republic) as described previously [5]. Mice were intravenously injected with $15 \mu \mathrm{g}$ of M1 protein in phosphate-buffered saline (PBS). M1 protein was purified from a mutated $S$. pyogenes strain [8] making the likelihood of endotoxin contamination close to zero; we also measured the endotoxin content in the M1 protein samples and confirmed that endotoxin levels were below the detection limit. Sham mice received PBS intravenously (i.v.) only. Vehicle or the Rhokinase inhibitor, Y-27632 (Calbiochem, San Diego, Calif., USA), was given $(0.5$ or $5 \mathrm{mg} / \mathrm{kg})$ intraperitoneally (i.p.) $10 \mathrm{~min}$ prior to M1 protein challenge. Animals were reanesthetized $4 \mathrm{~h}$ after the M1 protein challenge. The left lung was ligated and excised for edema measurement. The right lung was used for collecting bronchoalveolar lavage fluid (BALF) to quantify neutrophils. The lung was then excised, one lobe was fixed in formaldehyde for histology and the remaining tissue was snap-frozen in liquid nitrogen and stored at $-80^{\circ} \mathrm{C}$ for later myeloperoxidase (MPO) assays and enzyme-linked immunosorbent assay (ELISA) as to be described.

\section{Systemic Leukocyte Counts}

Blood was collected from the tail vein and mixed with Turk's solution (0.2 mg gentian violet in $1 \mathrm{ml}$ glacial acetic acid, 6.25\% $\mathrm{v} / \mathrm{v}$ ) in a 1:20 dilution. Leukocytes were identified as monomorphonuclear (MNL) and polymorphonuclear (PMNL) cells in a Burker chamber. 


\section{Lung Edema}

The left lung was excised, washed in PBS, dried gently with blotting paper and weighed. The tissue was then dried at $60^{\circ} \mathrm{C}$ for $72 \mathrm{~h}$ and reweighed. The change in the ratio of wet-weight to dryweight was used as indicator of lung edema formation.

\section{MPO Activity}

Lung tissue was thawed and homogenized in $1 \mathrm{ml}$ of $0.5 \%$ hexadecyltrimethylammonium bromide. Samples were freezethawed, after which the MPO activity of the supernatant was determined spectrophotometrically as the MPO-catalyzed change in absorbance in the redox reaction of $\mathrm{H}_{2} \mathrm{O}_{2}(450 \mathrm{~nm}$, with a reference filter $540 \mathrm{~nm}, 25^{\circ} \mathrm{C}$ ) as previously described [30]. Values were expressed as MPO unit per gram of tissue.

\section{ELISA}

Levels of MIP-2 and KC in lung homogenates were analyzed by using double antibody Quantikine ELISA kits (R \& D Systems, Europe, Abingdon, Oxon, UK) using recombinant murine MIP-2 and $\mathrm{KC}$ as standards. The lower limit of the assay was $0.5 \mathrm{pg} / \mathrm{ml}$.

\section{Flow Cytometry}

For analysis of surface molecule expression on circulating neutrophils, blood was collected (1:10 acid citrate dextrose) $4 \mathrm{~h}$ after the M1 protein challenge and incubated (for $10 \mathrm{~min}$ at room temperature) with an anti-CD16/CD32 antibody for blocking Fcy III/II receptors to reduce nonspecific labeling. It was then incubated with PE-conjugated anti-Gr-1 (clone RB6-8C5, rat IgG2b, eBioscience, San Diego, Calif., USA), and FITC-conjugated antiMac-1 (clone M1/70, integrin $\alpha_{M}$ china, rat IgG2b). The mean fluorescence intensity (MFI) was determined by comparisons to an isotype control antibody (FITC-conjugated rat IgG2b). All antibodies were purchased from BD Biosciences Pharmingen, San Jose, Calif., USA except when indicated otherwise. Cells were fixed and erythrocytes were lysed by BD lysis buffer (BD Biosciences) and the neutrophils were recovered following centrifugation. Flow cytometric analysis was performed by first gating the neutrophil population of cells based on forward and side scatter characteristics. Mac-1 expression was then determined on $\mathrm{Gr}-1^{+}$ cells in these gates on a FACSCalibur flow cytometer (Becton Dickinson, Mountain View, Calif., USA). A viable gate was used to exclude dead and fragmented cells.

\section{Histology}

Lung samples were fixed in $4 \%$ formaldehyde phosphate buffer overnight and then dehydrated and paraffin-embedded. Six-micrometer sections were stained with haematoxylin and eosin. Lung injury was quantified in a blinded manner by adoption of a preexisting scoring system as described [31], including the size of alveolar spaces, the thickness of alveolar septas, alveolar fibrin deposition and neutrophil infiltration graded on a $0-4$ (absentextensive) scale.

\section{In vitro Activation of Neutrophils}

Blood was collected from healthy animals containing 1:10 acid citrate dextrose. Whole blood was incubated with M1 protein $(1 \mu \mathrm{g} / \mathrm{ml})$ and Y-27632 $(10 \mu \mathrm{M}$, Sigma Chemical, St. Louis, Mo., USA) or vehicle at $37^{\circ} \mathrm{C}$ for $20 \mathrm{~min}$. Cells were stained for flow cytometric analysis of Mac-1 expression on neutrophils $\left(\mathrm{Gr}-1^{+}\right)$as described above.

\section{Western Blot}

Lung sections were weighed and homogenized in lysing buffer. The samples were centrifuged at 14,000 rpm for $5 \mathrm{~min}$ and $25 \mu \mathrm{l}$ of the supernatants were loaded onto SDS-polyacrylamide gel electrophoresis and transferred onto immunoblot membranes. The membranes were blocked with non-fat milk for $2 \mathrm{~h}$ and incubated with an anti-phospho-p38 MAPK monoclonal antibody (Thr180/Tyr182) or an anti-p38 MAPK antibody (Cell Signaling Technology, Beverly, Mass., USA). The membranes were then washed three times and incubated with a horseradish peroxidasecoupled secondary antibody (Santa Cruz Biotechnology, Santa Cruz, Calif., USA) for $2 \mathrm{~h}$. Blots were again washed 3 times and developed by the ECL ${ }^{\circledR}$ detection system (Santa Cruz Biotechnology). The resultant signal was quantified by using densitometer (GS-800 ${ }^{\mathrm{TM}}$ Calibrated Densitometer, BIO-RAD) and the values obtained from the sham animals were set as 100 .

\section{Quantitative RT-PCR}

Alveolar macrophages were isolated as previously described [32], 30 min after challenge with M1 protein. Total RNA was then isolated from alveolar macrophages by use of RNeasy Mini Kit (Qiagen, West Sussex, UK) and treated with RNase-free DNase (DNase I; Amersham Pharmacia Biotech, Sollentuna, Sweden) to remove potential genomic DNA contaminants. RNA concentrations were determined by measuring the absorbance at $260 \mathrm{~nm}$. Each cDNA was synthesized by reverse transcription from $10 \mu \mathrm{g}$ of total RNA by use of StrataScript first-strand synthesis system and random hexamers primers (Stratagene, AH Diagnostics, Stockholm, Sweden). Real-time PCR was performed using a Brilliant SYBRgreen QPCR master mix and MX 3000P detection system (Stratagene). The primer sequences of MIP-2, KC and $\beta$-actin were as follows: MIP-2 (f) 5'-GCT TCC TCG GGC ACT CCA GAC-3', MIP-2 (r) 5'-TTA GCC TTG CCT TTG TTC AGT AT-3'; KC (f) 5'-GCC AAT GAG CTG CGC TGT CAA TGC-3', KC (r) $5^{\prime}$-CTT GGG GAC ACC TTT TAG CAT CTT-3'; $\beta$-actin (f) $5^{\prime}$ ATG TTT GAG ACC TTC AAC ACC-3', $\beta$-actin (r) 5'-TCT CCA GGG AGG AAG AGG AT-3'. Standard PCR curves were generated for each PCR product to establish linearity of the RT-PCR reaction. PCR amplifications were performed in a total volume of $50 \mu \mathrm{l}$, containing $25 \mu \mathrm{l}$ of SYBRgreen PCR $2 \times$ master mix, 2 $\mu \mathrm{l}$ of $0.15 \mu \mathrm{M}$ of each primer, $0.75 \mu \mathrm{l}$ of reference dye, and $1 \mu \mathrm{l}$ of cDNA as a template adjusted up to $50 \mu \mathrm{l}$ with water. PCR reactions started at a denaturing temperature of $95^{\circ} \mathrm{C}$ for $10 \mathrm{~min}$, followed by a total of 40 cycles $\left(95^{\circ} \mathrm{C}\right.$ for $30 \mathrm{~s}$ and $55^{\circ} \mathrm{C}$ for $\left.1 \mathrm{~min}\right)$ and 1 min of elongation at $72^{\circ} \mathrm{C}$. The relative differences in expression between groups were expressed by using cycling time values. Cycling time values for the specific target genes were first normalized with that of $\beta$-actin in the same sample; relative differences between groups were then expressed as percentages of the control.

\section{Statistics}

Data are presented as mean values \pm standard errors of the means (SEM). Statistical evaluations were performed using Kruskal-Wallis 1-way analysis of variance on ranks followed by multiple comparisons versus the control group (Dunnett's method). $\mathrm{p}<0.05$ was considered significant and $n$ represents the number of animals in each group. 


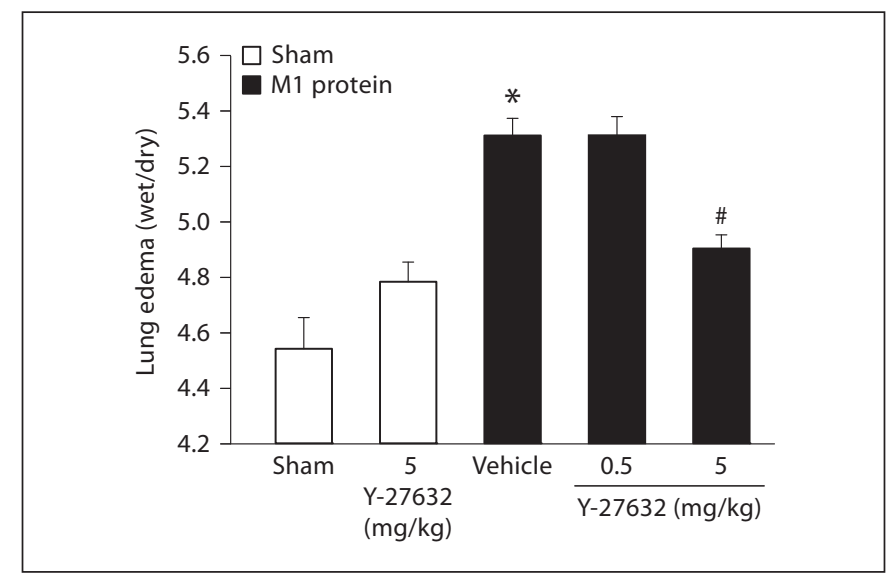

Fig. 1. Edema formation in the lung. Mice were treated with the Rho-kinase inhibitor Y-27632 (0.5 or $5 \mathrm{mg} / \mathrm{kg}$ ) or vehicle (PBS) 10 min prior to M1 protein injection. Mice treated with PBS served as sham animals. One group of mice was given $5 \mathrm{mg} / \mathrm{kg}$ Y-27632 alone without M1 protein injection. Data represents mean \pm SEM, ${ }^{*} \mathrm{p}<0.05$ versus sham and ${ }^{\#} \mathrm{p}<0.05$ versus vehicle $+\mathrm{M} 1$ protein, $\mathrm{n}=5$.

Table 1. Systemic leukocyte differential counts

\begin{tabular}{llll}
\hline & MNL & PMNL & Total \\
\hline Sham & $3.7 \pm 0.2$ & $1.5 \pm 0.1$ & $5.2 \pm 0.2$ \\
Vehicle + M1 protein & $0.9 \pm 0.1^{*}$ & $0.3 \pm 0.0^{*}$ & $1.2 \pm 0.1^{*}$ \\
Y-27632 (0.5) + M1 protein & $1.7 \pm 0.2^{* *}$ & $0.6 \pm 0.1$ & $2.3 \pm 0.3^{* *}$ \\
Y-27632 (5) + M1 protein & $1.7 \pm 0.1^{* *}$ & $0.8 \pm 0.1^{* *}$ & $2.4 \pm 0.4^{* *}$ \\
\hline
\end{tabular}

Blood was collected from sham animals receiving PBS i.v. only as well as from mice pretreated i.p. with vehicle (PBS) or Y-27632 $(0.5$ or $5 \mathrm{mg} / \mathrm{kg}) 10 \mathrm{~min}$ prior to M1 protein challenge for $4 \mathrm{~h}$. Cells were identified as MNL and PMNL.

Data represents mean \pm SEM, $10^{6}$ cells $/ \mathrm{ml}$ and $n=5$.

${ }^{*} \mathrm{p}<0.05$ versus sham, $\mathrm{n}=5$.

${ }^{* *} \mathrm{p}<0.05$ versus vehicle $+\mathrm{M} 1$ protein, $\mathrm{n}=5$.

\section{Results}

\section{Pulmonary Edema and Damage}

Challenge with M1 protein induced clear-cut lung injury, indicated by the significant increase in lung edema formation (fig. 1). Thus, the lung wet:dry ratio increased in $\mathrm{M} 1$ protein-treated animals from $4.6 \pm 0.1$ to $5.3 \pm$ 0.06 (fig. 1). Administration of $5 \mathrm{mg} / \mathrm{kg}$ of the Rho-kinase inhibitor Y-27632 reduced the ratio to $4.9 \pm 0.05$ in mice challenged with M1 protein (fig. 1). Although not significant, lung edema tended to be higher in mice receiving
$5 \mathrm{mg} / \mathrm{kg}$ of Y-27632 alone. Thus, inhibition of Rho-kinase signaling decreased M1 protein-provoked lung edema by $53 \%$. Moreover, morphologic examination revealed normal lung microarchitecture in sham-operated mice (fig. $2 \mathrm{a}$ ), whereas $\mathrm{M} 1$ protein caused clear-cut destruction of the lung tissue structure characterized by interstitial edema, capillary congestion and neutrophil accumulation (fig. 2c). It was observed that inhibition of Rho-kinase activity reduced M1 protein-provoked changes of the microarchitecture and neutrophil accumulation in the lung (fig. 2d, e). Quantification of the morphological changes revealed that $\mathrm{M} 1$ protein increased the lung injury score and that administration of the Rho-kinase inhibitor significantly decreased the score in animals challenged with M1 protein (fig. 2f).

\section{Neutrophil Infiltration}

Injection of M1 protein increased lung levels of MPO by more than 13-fold (fig. 3a). Inhibition of Rho-kinase signaling reduced the M1 protein-provoked increase in pulmonary MPO activity by $54 \%$ (fig. 3a). Quantification of BALF neutrophils revealed a massive enhancement in the number of alveolar neutrophils $4 \mathrm{~h}$ after administration of M1 protein (fig. 3b). We observed that treatment with $5 \mathrm{mg} / \mathrm{kg}$ of Y-27632 reduced the number of pulmonary neutrophils from $96.0 \pm 6.2 \times 10^{3}$ to $49.6 \pm 3.7 \times$ $10^{3}$ in the lung, corresponding to a $66 \%$ reduction $4 \mathrm{~h}$ after the M1 protein challenge (fig. $3 \mathrm{~b}$ ). Moreover, it was found that administration of M1 protein reduced the number of PMNLs and MNLs in the blood (table 1). Inhibition of Rho-kinase signaling significantly reduced this M1 protein-provoked leukocopenia (table 1).

\section{Mac-1 Expression and CXC Chemokine Formation}

Challenge with M1 protein greatly increased neutrophil expression of Mac-1 compared to PBS-treated control mice (fig. 4). We found that inhibition of Rho-kinase activity abolished M1 protein-induced increases of Mac-1 expression on the surface of neutrophils (fig. 4), suggesting that Rho-kinase signaling controls M1 protein-provoked expression of Mac-1 on neutrophils in vivo. In order to determine whether this inhibitory impact of Rhokinase inhibition is a direct or indirect effect, neutrophils were incubated with M1 protein with or without Y-27632 in vitro. We observed that M1 protein enhanced expression of Mac-1 on neutrophils in vitro, although this increase was lower than that observed in vivo (fig. 5). Coincubation with the Rho-kinase inhibitor had no impact on M1 protein-induced Mac-1 expression on neutrophils in vitro (fig. 5), indicating that the inhibitory effect of 
Fig. 2. Representative hematoxylin \& eosin sections of lung. a Sham animals were treated with PBS only. b They were given $5 \mathrm{mg} / \mathrm{kg}$ Y-27632 alone. Separate mice were pretreated with vehicle (PBS) (c) and 0.5 (d) or $5 \mathrm{mg} / \mathrm{kg}$ Y-27632 (e) $10 \mathrm{~min}$ prior to M1 protein administration. Samples were harvested $4 \mathrm{~h}$ after M1 protein challenge. Scale bar indicates $100 \mu \mathrm{m}$. f Histology score of lung injury. Data represents mean \pm SEM, ${ }^{*} \mathrm{p}<0.05$ versus sham and ${ }^{*} \mathrm{p}<0.05$ versus vehicle + M1 protein, $\mathrm{n}=5$.
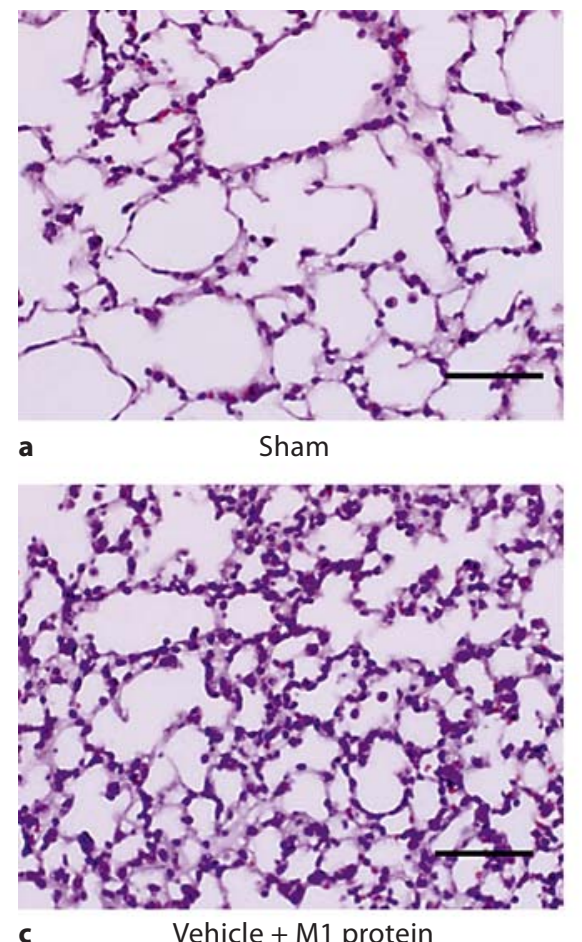

c

Vehicle + M1 protein

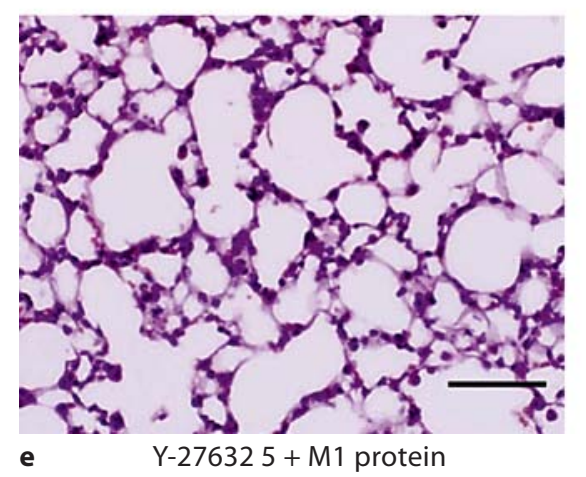

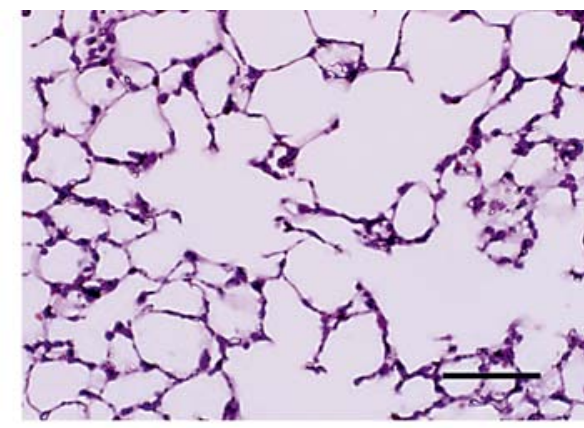

b

Y-27632 5

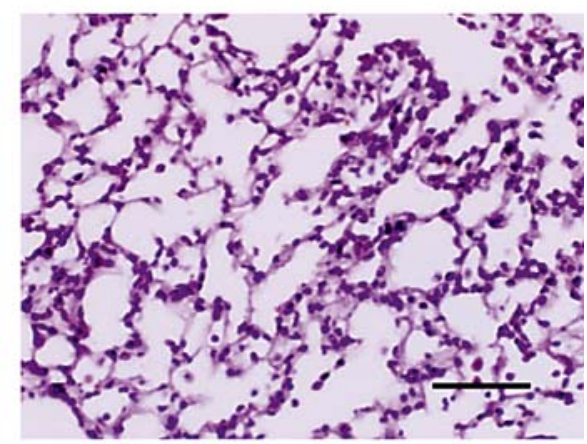

$\mathrm{Y}-276320.5+\mathrm{M} 1$ protein

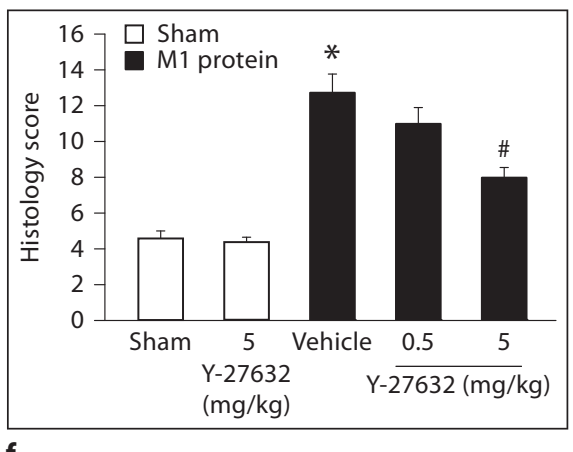

Y-27632 is an indirect effect in vivo. In vivo, it has recently been shown that the CXCL2-CXCR2 axis regulates neutrophil expression of Mac-1 in M1 protein-induced inflammation [33]. So, next we analyzed the role of Rhokinase signaling in regulating pulmonary formation of CXC chemokines in vivo. Lung levels of MIP-2 and KC were low in sham-operated animals whereas administration of M1 protein caused a more than 116-fold increase in CXC chemokine production in the lung (fig. 6a). We observed that treatment with Y-27632 dose-dependently reduced M1 protein-provoked production of MIP-2 and $\mathrm{KC}$ in the lung (fig. 6a). We next isolated alveolar macrophages from the BALF in animals challenged with M1 protein and/or Y-27632. We observed that Y-27632 mark- edly reduced mRNA levels of MIP-2 and KC in the alveolar macrophages in M1 protein-treated animals (fig. 6b).

\section{Phosphorylation of 338 MAPK}

We have recently observed that p38 MAPK activity plays a central role in M1 protein-induced neutrophil infiltration and lung injury [27]. Next, we asked whether Rho-kinase signaling and p38 MAPK phosphorylation might be related in M1 protein-induced lung inflammation. Herein, it was found that administration of M1 protein enhanced p38 MAPK phosphorylation in the lung (fig. 7). Administration of $5 \mathrm{mg} / \mathrm{kg}$ of the Rho-kinase inhibitor significantly decreased M1 protein-induced phosphorylation of p38 MAPK (fig. 7). 


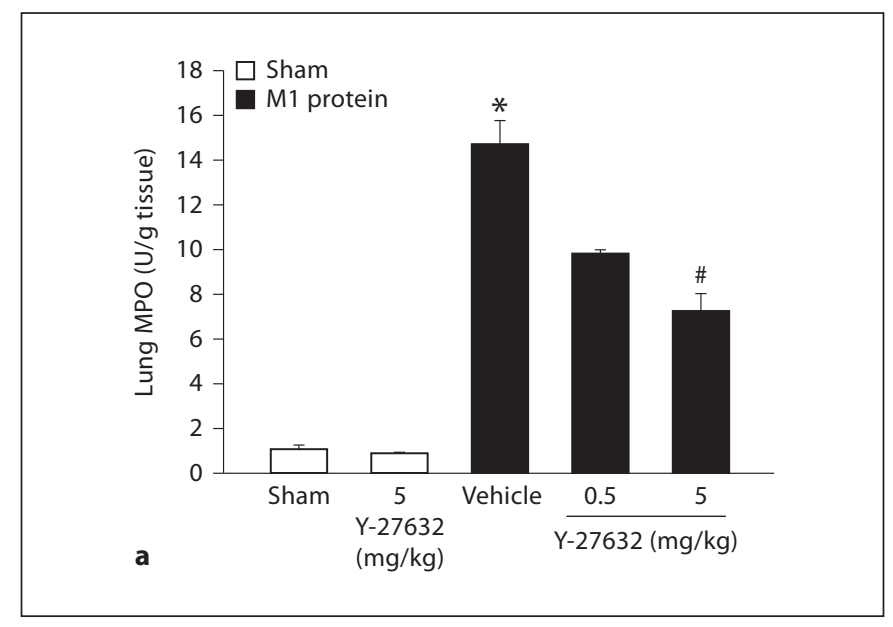

Fig. 3. Rho-kinase regulates $\mathrm{M} 1$ protein-induced pulmonary infiltration of neutrophils. a Lung MPO levels. b Number of BALF neutrophils in the lung. Animals were treated with Y-27632 (0.5 or $5 \mathrm{mg} / \mathrm{kg}$ ) or vehicle (PBS) $10 \mathrm{~min}$ prior to M1 protein injection.

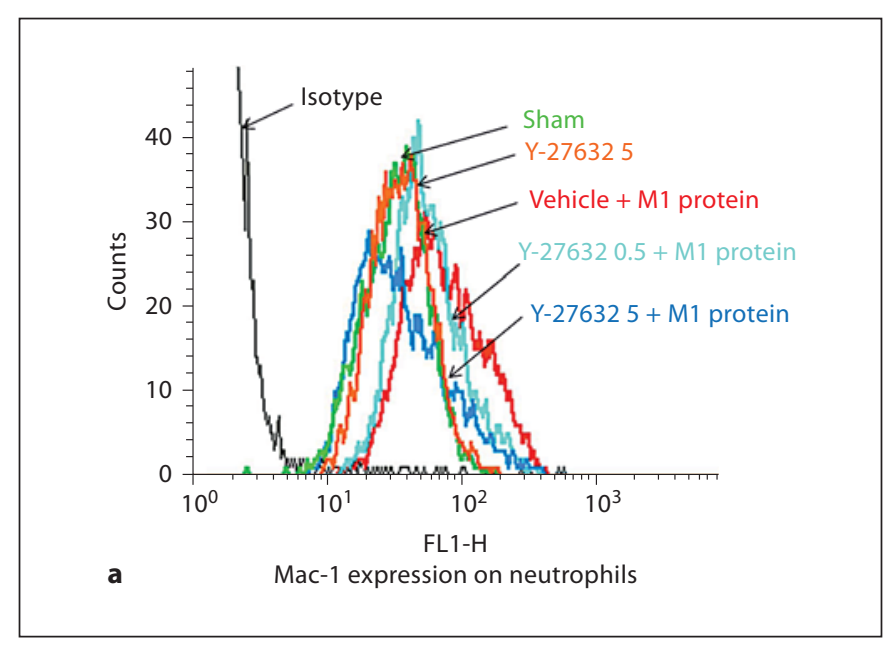

Fig. 4. Representative histogram from 5 samples: Rho-kinase regulates M1 protein-induced Mac-1 expression on neutrophils in vivo. Mac-1 expression on neutrophils in vehicle-treated (PBS) or Y-27632-treated $(0.5$ or $5 \mathrm{mg} / \mathrm{kg}$ ) animals $4 \mathrm{~h}$ after M1 protein in-

\section{Discussion}

This study documents that Rho-kinase signaling constitutes a key feature in streptococcal M1 protein-induced acute lung injury. The findings show that inhibition of Rho-kinase decrease M1 protein-provoked production of CXC chemokines, neutrophil activation and recruitment in the lung; in fact, it was observed that Rho-kinase inhibition not only decreased M1 protein-induced neutrophil

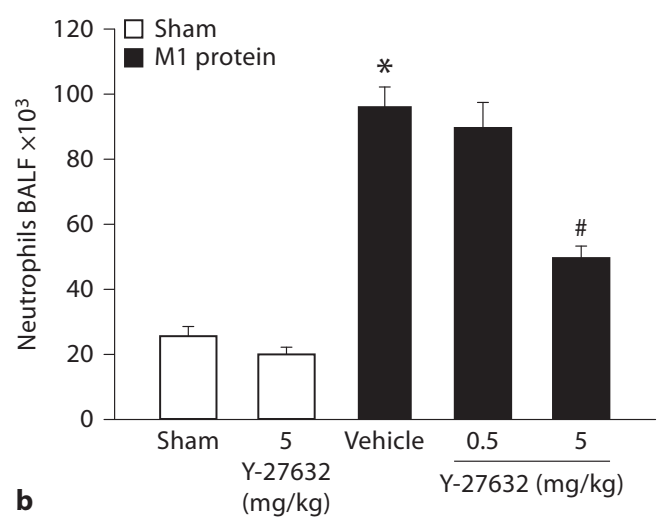

Samples were harvested $4 \mathrm{~h}$ after M1 protein challenge. Mice treated with PBS served as sham animals. One group of mice was given $5 \mathrm{mg} / \mathrm{kg}$ Y-27632 alone. Data represents mean $\pm \mathrm{SEM},{ }^{*} \mathrm{p}<0.05$ versus sham and ${ }^{\#} \mathrm{p}<0.05$ versus vehicle $+\mathrm{M} 1$ protein, $\mathrm{n}=5$.

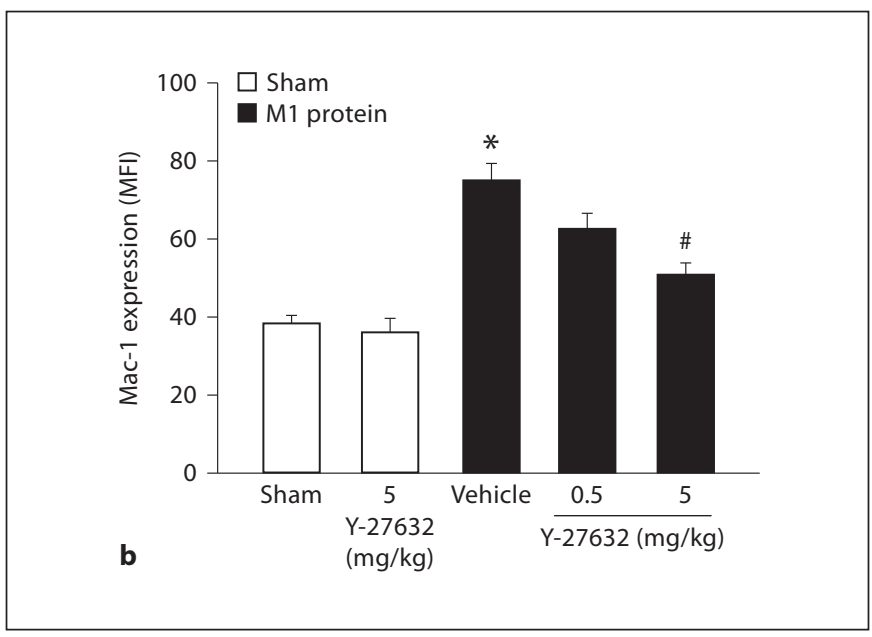

jection is shown. MFI is shown on the $\mathrm{x}$-axis and cell counts on the y-axis. Data represents mean $\pm \mathrm{SEM},{ }^{*} \mathrm{p}<0.05$ versus sham and ${ }^{\#} \mathrm{p}<0.05$ versus vehicle $+\mathrm{M} 1$ protein, $\mathrm{n}=5$.

infiltration but also abolished edema formation and tissue damage. Moreover, our data also indicate that phosphorylation of $\mathrm{p} 38 \mathrm{MAPK}$ is regulated by Rho-kinase signaling. Thus, these novel results indicate that targeting Rho-kinase signaling pathways may be an effective strategy to protect against acute lung damage in systemic streptococcal infections.

Potentially fatal streptococcal infections, such as STSS, are commonly triggered by $S$. pyogenes of the M1 sero- 


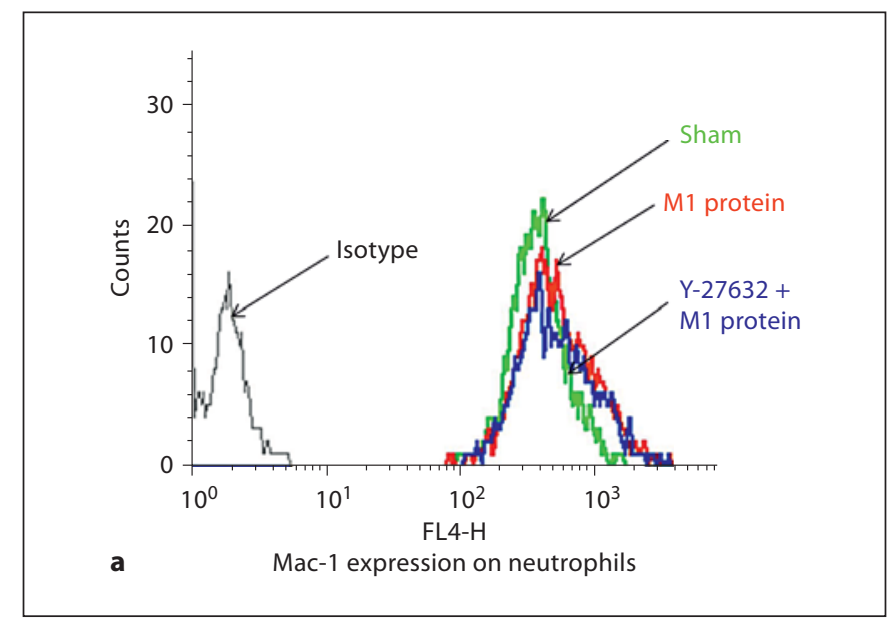

Fig. 5. Representative histogram from 5 samples: Mac-1 expression on neutrophils in vitro. Whole blood was incubated with PBS only, or M1 protein $(1 \mu \mathrm{g} / \mathrm{ml})$ and vehicle (PBS) or Y-27632 (10 $\mu \mathrm{M})$. Samples were harvested $4 \mathrm{~h}$ after M1 protein challenge. MFI

type [34]. During bacterial invasion, the M1 protein is shed from the surface of $S$. pyogenes into the blood circulation causing widespread activation of the host innate immune cells. Activated neutrophils and monocytes secrete massive levels of cytokines and chemokines [6,35], provoking a systemic inflammatory response, which may cause acute lung damage and compromise blood oxygenation, a feared complication in STSS. Recruitment of neutrophils to extravascular sites of inflammation is known to be a rate-limiting step in septic lung damage [36,37]. For example, ample data have demonstrated that immunoneutralization of specific adhesion molecules, such as ICAM-1, Mac-1, LFA-1 and PSGL-1, not only decreases neutrophil infiltration but also ameliorates acute lung damage in endotoxemia and abdominal sepsis $[8,38]$. Herein, we found that Rho-kinase inhibition reduced lung MPO activity and the number of neutrophils in the bronchoalveolar space in animals exposed to M1 protein, suggesting that Rho-kinase signaling is a significant regulator of neutrophil trafficking in strepotococcal M1 protein-induced acute lung injury. Considering the mechanistic relationship between neutrophil infiltration and tissue injury, it may be suggested that, at least, a part of the pulmonary protection provided by interference with Rho-kinase signaling is due to the inhibition of neutrophil accumulation in the lung. A recent study reported that activation and upregulation of Mac-1 on neutrophils are key components at the initiation of acute lung damage caused by streptococcal M1 protein [14]. Indeed, Mac-1 is

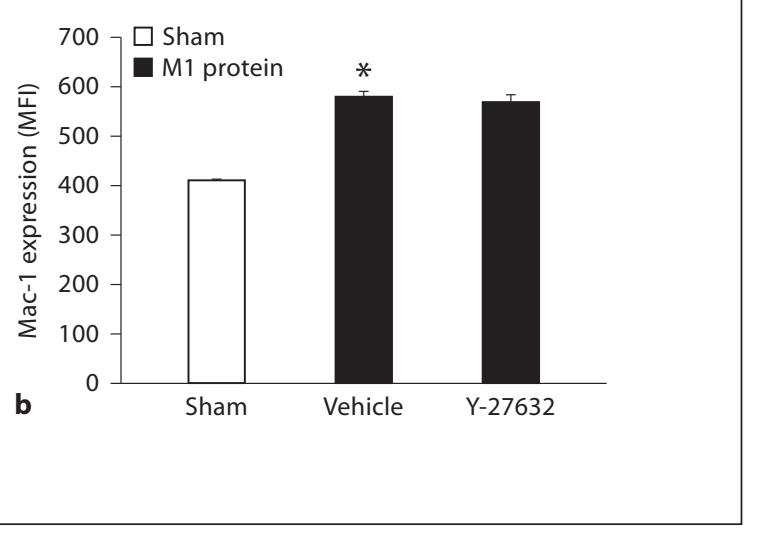

is shown on the $\mathrm{x}$-axis and cell counts on the $\mathrm{y}$-axis. Data represents mean \pm SEM, ${ }^{*} \mathrm{p}<0.05$ vs. Sham and ${ }^{\#} \mathrm{p}<0.05$ vs. Vehicle $+\mathrm{M} 1$ protein, $\mathrm{n}=5$.

not only a marker of neutrophil activation but also a fundamental adhesion molecule mediating the infiltration of neutrophils into the lung in endotoxemia and polymicrobial sepsis $[8,39]$. Due to the potent reduction in pulmonary neutrophils in mice treated with the Rho-kinase inhibitor, we next asked whether Rho-kinase might regulate Mac-1 expression on the surface of neutrophils in M1 protein-induced lung damage. Our study found that targeting Rho-kinase activity markedly reduced M1 protein-provoked expression of Mac-1 on neutrophils in vivo, suggesting that inhibition of neutrophil expression Mac-1 may help explain the inhibitory impact of the Rhokinase inhibitor on neutrophil accumulation and tissue injury in streptococcal M1 protein lung damage. Notably, we also found that Rho-kinase inhibition had no direct effect on M1 protein-induced upregulation of Mac-1 on neutrophils in vitro, suggesting that Rho-kinase signaling does not regulate M1 protein-induced Mac-1 expression in neutrophils.

Tissue navigation of neutrophils is coordinated by secreted chemokines. Neutrophil activation and trafficking are controlled by CXC chemokines, such as MIP-2 and KC [40]. Realizing that Rho-kinase did not directly regulate Mac-1 upregulation on neutrophils, we hypothesized that the Rho-kinase-dependent expression of Mac-1 on neutrophils was mediated by secreted CXC chemokines in streptococcal M1 protein-provoked lung damage. We observed that Rho-kinase inhibition markedly suppressed M1 protein-induced pulmonary generation of MIP-2 and 


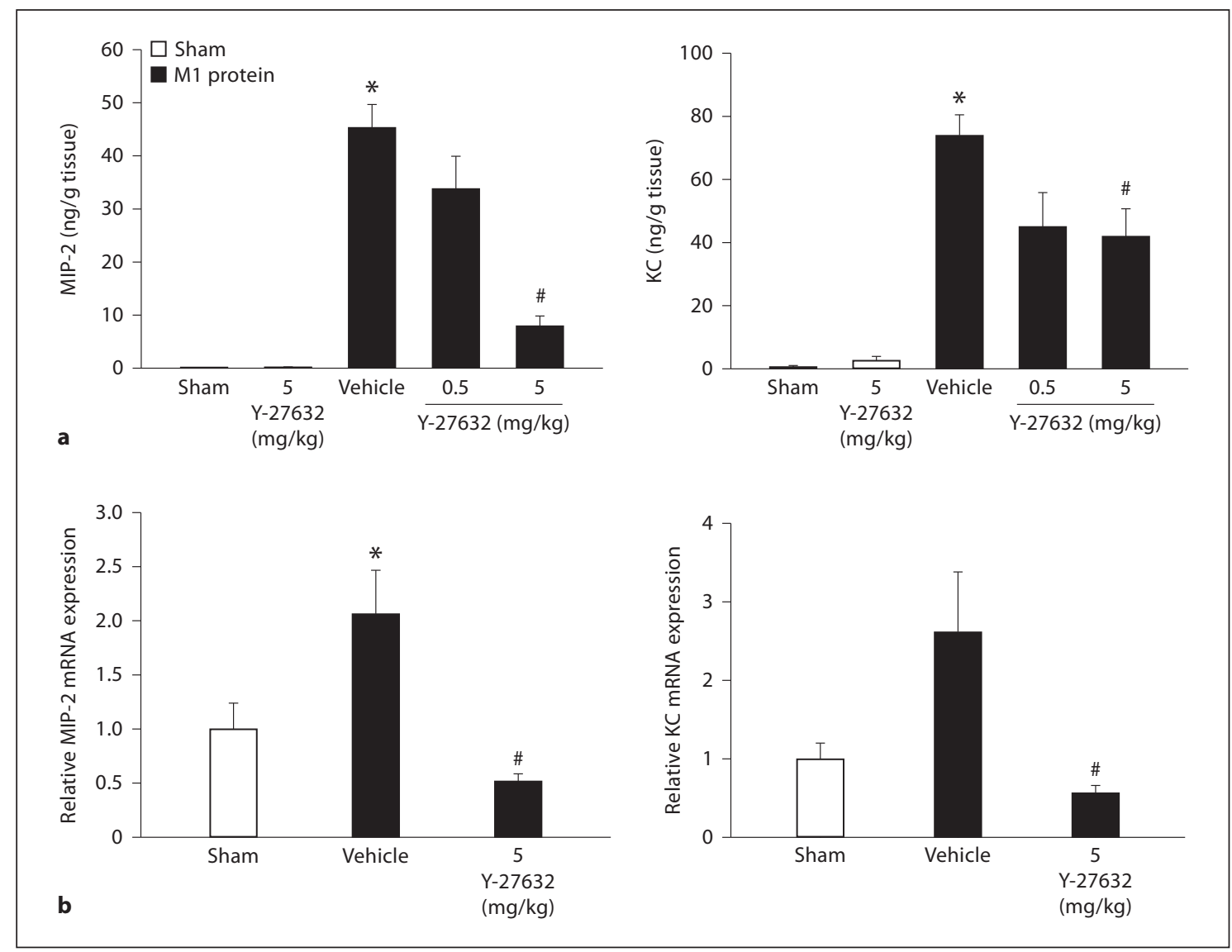

Fig. 6. Rho-kinase regulates CXC chemokine formation in the lung. Animals were treated with Y-27632 (0.5 or $5 \mathrm{mg} / \mathrm{kg}$ ) or vehicle (PBS) $10 \mathrm{~min}$ prior to M1 protein injection. Mice treated with PBS served as sham animals. One group of mice was given Y-27632 (5 mg/kg) only. a ELISA was used to quantify the levels of MIP-2 and KC in the lungs of mice $4 \mathrm{~h}$ after M1 protein challenge. $\mathbf{b}$ Quantitative RT-PCR was used to determine mRNA levels of MIP-2 and KC in alveolar macrophages $30 \mathrm{~min}$ after M1 protein injection. Levels of MIP-2 and KC mRNA were normalized to mRNA levels of $\beta$-actin. Data represents mean $\pm S E M,{ }^{*} p<0.05$ versus sham and ${ }^{\#} p<$ 0.05 versus vehicle + M1 protein, $\mathrm{n}=5$.

KC. Notably, Rho-kinase inhibition greatly reduced the gene expression of MIP-2 and KC in alveolar macrophages, suggesting that Rho-kinase activity is an important feature in macrophage production of CXC chemokines in streptococcal infections. Knowing that CXC chemokines and their receptor CXCR2 are critical in mediating M1 protein-induced neutrophil expression of Mac-1 [33], our data suggest that inhibition of CXC chemokine formation helps to explain the inhibitory effect of the Rho-kinase inhibitor on neutrophil activation, i.e. Mac-1 expression, and recruitment into the lung in response to streptococcal M1 protein. Considered together, this is the first study to demonstrate that Rho-kinase signaling exerts a significant function in streptococcal M1 protein-induced inflammation and tissue injury in the lung. In this context, it should be mentioned that these findings do not necessarily exclude a potential role of other kinases in M1 protein-provoked lung damage. Because we have recently observed that p38 MAPK is a critical regulator of CXC chemokine formation and neutrophil recruitment in M1 protein-provoked lung damage [29], it was of interest to test whether Rho-kinase signaling might control phosphorylation of $\mathrm{p} 38 \mathrm{MAPK}$ in response to M1 protein challenge. It was found that inhibition of Rhokinase markedly suppressed M1 protein-induced phosphorylation of p38 MAPK in the lung. This observation suggests that Rho-kinase signaling and p38 MAPK signaling in streptococcal infections might be related. 


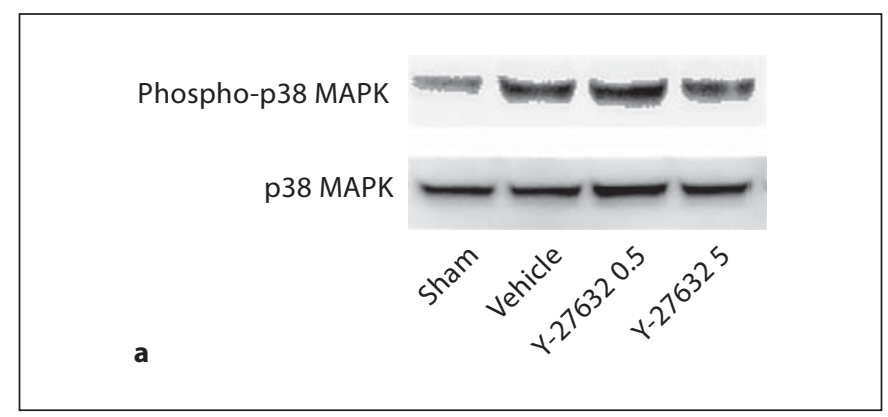

Fig. 7. Phosphorylation of p38 MAPK. Sham animals received only PBS. Mice were pretreated i.p. with vehicle (PBS) or Y-27632 $(0.5$ or $5 \mathrm{mg} / \mathrm{kg}) 10 \mathrm{~min}$ prior to M1 protein challenge. Samples were harvested $4 \mathrm{~h}$ after M1 protein challenge. a Western blot analysis of extracts from lung tissue (see Materials and Methods for details) using an anti-phospho-p38 MAPK antibody (upper)

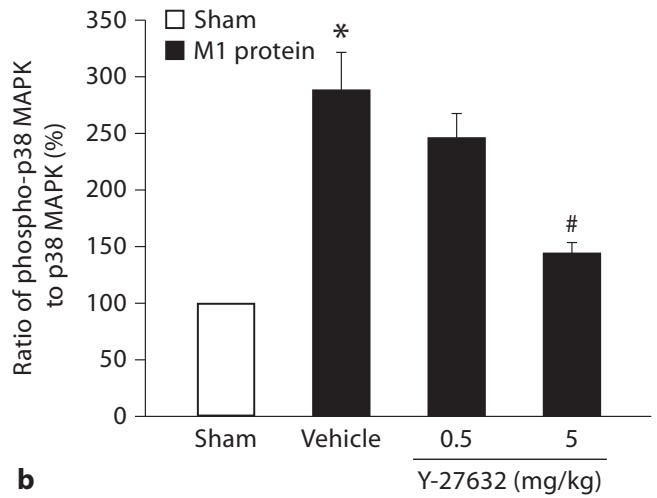

or an anti-p38 MAPK antibody (lower). b Band intensities were quantified by densitometry and the ratio of phospho-p38 MAPK expression to total p38 MAPK expression is shown. Data represents mean \pm SEM, ${ }^{*} p<0.05$ versus sham and ${ }^{*} p<0.05$ versus vehicle + M1 protein, $\mathrm{n}=3$.
Taken together, these novel findings show that Rhokinase inhibition attenuates CXC chemokine generation, neutrophil activation and recruitment in M1 proteinprovoked pulmonary edema formation and tissue injury. Moreover, our data suggest that Rho-kinase signaling regulates p38 MAPK activity in the lung in response to streptococcal M1 protein. In conclusion, these results suggest that targeting the Rho-kinase signaling pathway may be a useful way to ameliorate pulmonary damage in severe infections caused by $S$. pyogenes.

\section{Acknowledgments}

This work was supported by grants from the Swedish Medical Research Council (2009-4872 and 2008-7480), Crafoordska Stiftelsen, Einar och Inga Nilssons Stiftelse, Harald och Greta Jaenssons Stiftelse, Greta och Johan Kocks Stiftelser, Fröken Agnes Nilssons Stiftelse, Franke och Margareta Bergqvists Stiftelse för Främjande av Cancerforskning, Magnus Bergvalls Stiftelse, Mossfelts Stiftelse, Nanna Svartz Stiftelse, Ruth och Richard Julins Stiftelse, Svenska Läkaresällskapet, Allmäna Sjukhusets i Malmö Stiftelse för Bekämpande av Cancer, MAS fonder, Malmö University Hospital and Lund University.

\section{References}

-1 Cervera C, Almela M, Martinez-Martinez JA, Moreno A, Miro JM: Risk factors and management of Gram-positive bacteraemia. Int J Antimicrob Agents 2009;34(suppl 4):S26-S30.

2 DiPiro JT: Pathophysiology and treatment of gram-negative sepsis. Am J Hosp Pharm 1990;47(11 suppl 3):S6-S10.

-3 Martin GS, Mannino DM, Eaton S, Moss M: The epidemiology of sepsis in the United States from 1979 through 2000. N Engl J Med 2003;348:1546-1554.

4 Cunningham MW: Pathogenesis of group A streptococcal infections. Clin Microbiol Rev 2000;13:470-511.

$>5$ Collin M, Olsen A: Generation of a mature streptococcal cysteine proteinase is dependent on cell wall-anchored M1 protein. Mol Microbiol 2000;36:1306-1318.
6 Pahlman LI, Malmstrom E, Morgelin M, Herwald H: M protein from Streptococcus pyogenes induces tissue factor expression and pro-coagulant activity in human monocytes. Microbiology 2007;153:2458-2464.

7 Pahlman LI, Morgelin M, Eckert J, Johansson L, Russell W, Riesbeck K, et al: Streptococcal M protein: a multipotent and powerful inducer of inflammation. I Immunol 2006;177:1221-1228.

$>8$ Asaduzzaman M, Zhang S, Lavasani S, Wang Y, Thorlacius H: LFA-1 and MAC-1 mediate pulmonary recruitment of neutrophils and tissue damage in abdominal sepsis. Shock 2008;30:254-259.

$\checkmark 9$ Tilanus AM, de Geus HR, Rijnders BJ, Dwarkasing RS, van der Hoven B, Bakker J: Severe group A streptococcal toxic shock syndrome presenting as primary peritonitis: a case re- port and brief review of the literature. Int J Infect Dis 2010;14(suppl 3):e208-e212.

10 Vuilleumier H, Halkic N: Streptococcal toxic shock syndrome revealed by a peritonitis. Case report and review of the literature. Swiss Surg 2001;7:25-27.

11 Bacon KB, Oppenheim JJ: Chemokines in disease models and pathogenesis. Cytokine Growth Factor Rev 1998;9:167-173.

12 Li X, Klintman D, Liu Q, Sato T, Jeppsson B, Thorlacius H: Critical role of CXC chemokines in endotoxemic liver injury in mice. J Leukoc Biol 2004;75:443-452.

13 Schramm R, Schaefer T, Menger MD, Thorlacius $\mathrm{H}$ : Acute mast cell-dependent neutrophil recruitment in the skin is mediated by KC and LFA-1: inhibitory mechanisms of dexamethasone. J Leukoc Biol 2002;72: 1122-1132. 
14 Zhang S, Zhang S, Rahman M, Herwald H, Thorlacius H: Streptococcal M1 protein-induced lung injury is independent of platelets in mice. Shock 2010;35:86-91.

$\checkmark 15$ Arcaroli J, Yang KY, Yum HK, Kupfner J, Pitts TM, Park JS, et al: Effects of catecholamines on kinase activation in lung neutrophils after hemorrhage or endotoxemia. J Leukoc Biol 2002;72:571-579.

16 Barton GM: A calculated response: control of inflammation by the innate immune system. J Clin Invest 2008;118:413-420.

17 Itoh K, Yoshioka K, Akedo H, Uehata M, Ishizaki T, Narumiya S: An essential part for Rho-associated kinase in the transcellular invasion of tumor cells. Nat Med 1999;5:221225.

- 18 Slotta JE, Braun OO, Menger MD, Thorlacius H: Fasudil, a Rho-kinase inhibitor, inhibits leukocyte adhesion in inflamed large blood vessels in vivo. Inflamm Res 2006;55: 364-367.

19 Niggli V: Rho-kinase in human neutrophils: a role in signalling for myosin light chain phosphorylation and cell migration. FEBS Lett 1999;445:69-72.

20 Slotta JE, Laschke MW, Menger MD, Thorlacius H: Rho-kinase signalling mediates endotoxin hypersensitivity after partial hepatectomy. Br J Surg 2008;95:976-984.

- 21 Kitamura K, Tada S, Nakamoto N, Toda K, Horikawa H, Kurita S, et al: Rho/Rho kinase is a key enzyme system involved in the angiotensin II signaling pathway of liver fibrosis and steatosis. J Gastroenterol Hepatol 2007; 22:2022-2033.

-22 Laschke MW, Dold S, Jeppsson B, Schilling MK, Menger MD, Thorlacius H: Rho-kinase inhibitor attenuates cholestasis-induced CXC chemokine formation, leukocyte recruitment, and hepatocellular damage in the liver. J Surg Res 2010;159:666-673.

-23 Santen S, Wang Y, Laschke MW, Menger MD, Jeppsson B, Thorlacius H: Rho-kinase signalling regulates $\mathrm{CXC}$ chemokine formation and leukocyte recruitment in colonic ischemia-reperfusion. Int J Colorectal Dis 2010;25:1063-1070.
4 Oka M, Fagan KA, Jones PL, McMurtry IF: Therapeutic potential of RhoA/Rho kinase inhibitors in pulmonary hypertension. Br J Pharmacol 2008; 155:444-454.

25 Awla D, Hartman H, Abdulla A, Zhang S, Rahman M, Regner S, et al: Rho-kinase signalling regulates trypsinogen activation and tissue damage in severe acute pancreatitis. $\mathrm{Br}$ J Pharmacol 2011;162:648-658.

26 Kumar S, Boehm J, Lee JC: p38 MAP kinases: key signalling molecules as therapeutic targets for inflammatory diseases. Nat Rev Drug Discov 2003;2:717-726.

27 Kuldo JM, Ogawara KI, Werner N, Asgeirsdottir SA, Kamps JA, Kok RJ, et al: Molecular pathways of endothelial cell activation for (targeted) pharmacological intervention of chronic inflammatory diseases. Curr Vasc Pharmacol 2005;3:11-39.

28 Xiao YQ, Malcolm K, Worthen GS, Gardai S, Schiemann WP, Fadok VA, et al: Cross-talk between ERK and p38 MAPK mediates selective suppression of pro-inflammatory cytokines by transforming growth factor-beta. J Biol Chem 2002;277:14884-14893.

29 Zhang S, Rahman M, Zhang S, Wang Y, Herwald $\mathrm{H}$, Jeppsson B, et al: p38 Mitogen-activated protein kinase signaling regulates streptococcal M1 protein-induced neutrophil activation and lung injury. J Leukoc Biol, 2012;91:137-145.

30 Asaduzzaman M, Rahman M, Jeppsson B, Thorlacius $\mathrm{H}$ : P-selectin glycoprotein-ligand-1 regulates pulmonary recruitment of neutrophils in a platelet-independent manner in abdominal sepsis. Br J Pharmacol 2009;156:307-315.

31 Borzone G, Liberona L, Olmos P, Saez C, Meneses M, Reyes T, et al: Rat and hamster species differences in susceptibility to elastase-induced pulmonary emphysema relate to differences in elastase inhibitory capacity. Am J Physiol Regul Integr Comp Physiol 2007;293:R1342-R1349.

32 Zhang X, Goncalves R, Mosser DM: The isolation and characterization of murine macrophages. Curr Protoc Immunol 2008; chapt 14:unit 14.1.
3 Zhang S, Rahman M, Zhang S, Qi Z, Herwald $\mathrm{H}$, Thorlacius $\mathrm{H}$ : Simvastatin regulates CXC chemokine formation in streptococcal M1 protein-induced neutrophil infiltration in the lung. Am J Physiol Lung Cell Mol Physiol 2011;300:L930-L939.

34 Pahlman LI, Olin AI, Darenberg J, Morgelin M, Kotb M, Herwald H, et al: Soluble M1 protein of Streptococcus pyogenes triggers potent T cell activation. Cell Microbiol 2008; 10: 404-414.

35 Ropert C, Closel M, Chaves AC, Gazzinelli RT: Inhibition of a $\mathrm{p} 38 / \mathrm{stress}$-activated protein kinase-2-dependent phosphatase restores function of IL-1 receptor-associate kinase- 1 and reverses Toll-like receptor 2- and 4-dependent tolerance of macrophages. J Immunol 2003;171:1456-1465.

36 Gao X, Xu N, Sekosan M, Mehta D, Ma SY, Rahman A, et al: Differential role of CD18 integrins in mediating lung neutrophil sequestration and increased microvascular permeability induced by Escherichia coli in mice. J Immunol 2001;167:2895-2901.

37 Kamochi M, Kamochi F, Kim YB, Sawh S, Sanders JM, Sarembock I, et al: P-selectin and ICAM-1 mediate endotoxin-induced neutrophil recruitment and injury to the lung and liver. Am J Physiol 1999;277:L310L319.

38 Herwald H, Cramer H, Morgelin M, Russell W, Sollenberg U, Norrby-Teglund A, et al: M protein, a classical bacterial virulence determinant, forms complexes with fibrinogen that induce vascular leakage. Cell 2004;116: 367-379.

-39 Menezes GB, Lee WY, Zhou H, Waterhouse CC, Cara DC, Kubes P: Selective down-regulation of neutrophil Mac-1 in endotoxemic hepatic microcirculation via IL-10. J Immunol 2009; 183:7557-7568

40 Zhang XW, Liu Q, Wang Y, Thorlacius $\mathrm{H}$ CXC chemokines, MIP-2 and KC, induce Pselectin-dependent neutrophil rolling and extravascular migration in vivo. Br J Pharmacol 2001;133:413-421. 